\title{
Evaluating the Educational Impact of Telehealth on Adolescent Medicine Trainees: a Qualitative Approach
}

\author{
Sarah A. Golub ${ }^{1,2}$ (D) Do-Quyen Pham ${ }^{1,2} \cdot$ Ema L. Bargeron $^{3} \cdot$ Cora Collette Breuner $^{1,2} \cdot$ Yolanda N. Evans $s^{1,2}$ \\ Accepted: 25 June 2021 / Published online: 13 July 2021 \\ (C) The Author(s), under exclusive licence to Springer Science+Business Media, LLC, part of Springer Nature 2021
}

\begin{abstract}
Purpose of Review Telehealth has been swiftly incorporated into clinical practice since the onset of the COVID-19 pandemic, with limited understanding of how it affects trainees' educational experiences. Our study evaluates the impact of telehealth on clinical education in pediatric and Adolescent Medicine trainees during the pandemic.

Recent Findings Previous literature on telehealth focused on provider and patient perceptions in addition to clinical education for students, though none has evaluated the experiences of medical residents and fellows in Adolescent Medicine.

Summary Trainees reported enhanced opportunities for bidirectional observation with attending physicians, increased flexibility for the trainee and families, and the opportunity to engage with adolescents in their home environment. Drawbacks include decreased physical exam skill-building and technological difficulties that can interrupt the learning experience. Telehealth is a valuable tool in clinical education and innovative strategies are needed to refine and enhance these educational experiences for pediatric and Adolescent Medicine trainees.
\end{abstract}

Keywords Telehealth $\cdot$ Medical education $\cdot$ Pediatric trainees $\cdot$ Adolescent Medicine

\section{Introduction}

Since the onset of the COVID-19 pandemic, medicine as we once knew it seemed to transform entirely. In a matter of weeks, we watched as nonessential clinical care came to a screeching halt, before picking up again and taking a completely new shape. Medical institutions and academic centers across the globe swiftly transitioned much of their outpatient clinical care to telehealth, resulting in a diminished capacity for in-person clinical training for some learners. Consequently, this shift dramatically changed our approaches to both teaching and practicing medicine, altering

This article is part of the Topical Collection on Technology and Pediatrics

Sarah A. Golub

sarah.golub@seattlechildrens.org

1 Division of Adolescent Medicine, Seattle Children's Hospital, 4540 Sand Point Way NE Suite 200, M/S CSB-200, PO Box 5371, Seattle, WA 98145-5005, USA

2 Department of Pediatrics, University of Washington School of Medicine, Seattle, WA, USA

3 Georgetown University, Washington, D.C., USA the landscape of medical education for many trainees. Though medical educators have proposed strategies to ensure the inclusion of learners during this unprecedented time, striking the balance between prioritization of patient and provider safety while keeping trainees engaged has proven to be an ongoing challenge [1]. Prior to the pandemic, few learners had reported much, if any, clinical experience with telehealth [2], yet many have now become comfortable and competent in utilizing this modality [3•]. Current telehealth literature from the past year focuses on provider and patient perceptions of telehealth [4], though fewer studies have focused on its direct impact on trainees' clinical education. The literature has shown that, despite the often complex and sensitive nature of interactions with patients, adolescent healthcare can be provided effectively and successfully through telehealth; however, the efficacy of this platform in clinical education has not been fully established $[5-7,8 \bullet, 9 \bullet]$. Since the early months of the pandemic, there has been a surge of publications on the importance of including learners in the virtual setting, though the majority of articles have focused on medical and nursing student education, with fewer studies examining the experiences of medical residents or clinical fellows $[3 \bullet, 10,11,12 \bullet \bullet]$. Several Adolescent Medicine divisions throughout the country have described the challenges, opportunities, and impact of a ramp-up to telehealth in the setting of COVID-19 [13-16]. 
However, to our knowledge, there have been no studies addressing its effect on clinical education specifically of Adolescent Medicine trainees. The aim of our study was to better understand the educational experience of pediatric and Adolescent Medicine trainees participating in clinical encounters via telehealth in the Adolescent Medicine clinic at a quaternary care academic children's hospital.

\section{Methods}

We administered an IRB-approved, web-based survey to residents and fellows (collectively referred to hereafter as trainees) rotating through the Adolescent Medicine clinic at a quaternary care academic pediatric hospital between March 2020 and April 2021. Initial request to complete the survey was sent by email, followed by a subsequent reminder email within 1-2 weeks. This was an 11-item anonymous questionnaire consisting of multiple-choice, Likert-scale, and free-text responses to elicit trainees' feedback regarding their experiences using telehealth. This work summarizes the qualitative component of this mixed-methods study. Freetext responses were analyzed by two reviewers independently to ensure inter-coder reliability, and a third reviewer was introduced to resolve any discrepancies in findings. Common themes were identified using a grounded theory approach and illustrative quotes were selected to demonstrate subthemes.

\section{Results}

We received completed surveys from 25 out of 53 trainees following their rotation through the Adolescent Medicine clinic (47\% response rate). Table 1 presents participants' level of training, future career plans, and their overall experiences with telehealth prior to and after the onset of the pandemic. The majority $(72 \%)$ reported no prior experience with telehealth before the pandemic. Most $(56 \%)$ attended over 5 telehealth clinic sessions by the end of their rotation.

Trainees described advantages and disadvantages of telehealth in their clinical education and in the delivery of healthcare for adolescent patients and their families. Thematic categories and representative quotes are displayed in Table 2. Overall, many trainees valued the ability to see teens in their home environment and found that observing and being observed by attending physicians were unique learning opportunities that would not have been as accessible in a traditional clinic model. They also found telehealth to be an efficient and flexible modality for clinical education. Trainees perceived that telehealth was more accessible for patients and their families by eliminating travel time and providing a safer option to access healthcare during the pandemic.
Table 1 Trainee characteristics and experience with telehealth

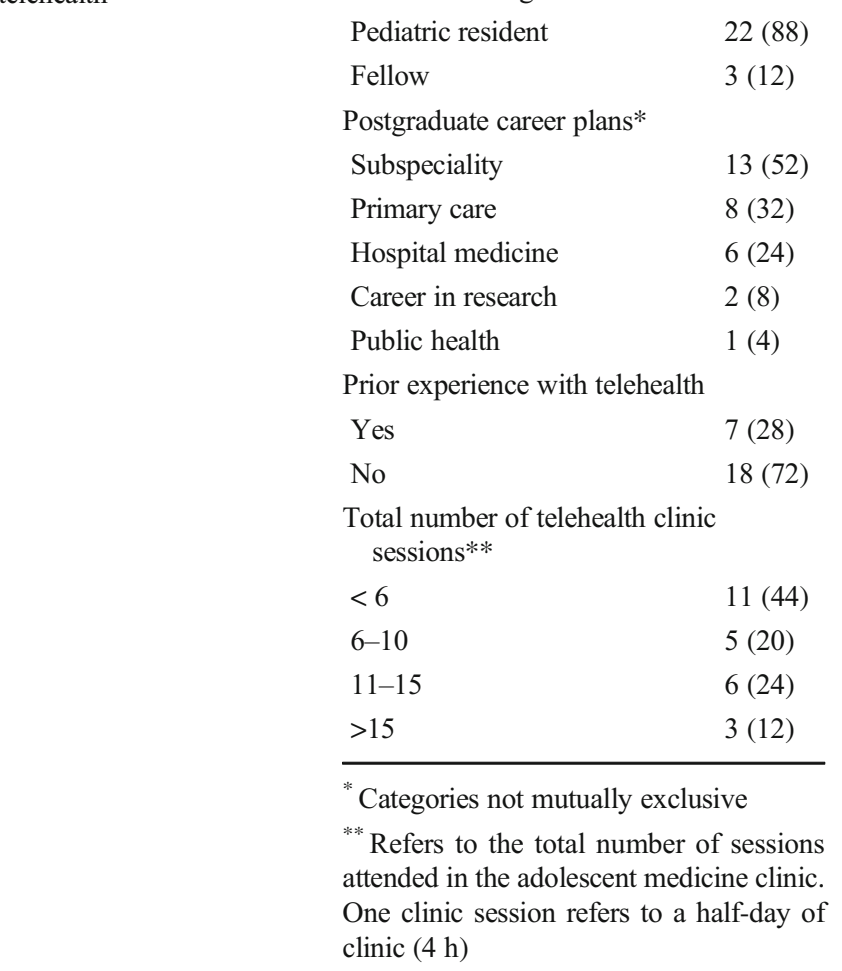

On the other hand, they noted that telehealth encounters often diminished the opportunity to build rapport with patients and connect emotionally with adolescents around sensitive topics. Trainees also reported that while increased supervision during telehealth visits was of value in ability to provide realtime feedback, it did have potential to reduce their autonomy. Lack of time between visits for dedicated teaching and inability to perform comprehensive physical exams were also reported as factors that detracted from trainees' educational experiences. Lastly, trainees also found that technical issues, including unstable internet connections, played a role in limiting educational experiences.

When solicited for recommendations on improving telehealth experiences for subsequent learners, trainees suggested maintaining time to discuss clinical cases before and after appointments. They reported increased sense of autonomy when attending physicians turned off their cameras during a visit and advocated for the incorporation of telehealth training in future curricula.

\section{Discussion}

Our findings suggest that trainees in our Adolescent Medicine clinic have had positive learning experiences with telehealth 
Table 2 Thematic analysis of the perceived advantages and disadvantages of telehealth on clinical education and healthcare delivery

\begin{tabular}{|c|c|c|}
\hline Theme & Subtheme & Quotes \\
\hline $\begin{array}{l}\text { Advantages of telehealth in } \\
\text { clinical education }\end{array}$ & $\begin{array}{l}\text { - Opportunity to see teens in } \\
\text { home environment } \\
\text { - Direct observation and real-time } \\
\text { feedback from attendings } \\
\text { - Benefit of observing attending } \\
\text { - Convenient, flexible, and } \\
\text { efficient for trainees to } \\
\text { participate }\end{array}$ & $\begin{array}{l}\text { "I think some adolescents opened up more when doing the confidential HEADSS, } \\
\text { as they felt more comfortable in their space... it allowed me to better see them as } \\
\text { a human as well—getting a peek into their life." } \\
\text { "I learned an incredible amount by being a strict observer during most visits as I } \\
\text { found that I had a lot of the same questions that patients/parents had. I felt that } \\
\text { there was some concern that our learning would suffer if we didn't participate or } \\
\text { lead parts of every visit, but I didn't find that to be the case." } \\
\text { "I really appreciated [the] attending texting me during the visit with tips and } \\
\text { questions to keep me on track." }\end{array}$ \\
\hline $\begin{array}{l}\text { Disadvantages of telehealth in } \\
\text { clinical education }\end{array}$ & $\begin{array}{l}\text { - Decreased rapport with patients } \\
\text { - Decreased autonomy for } \\
\text { trainees } \\
\text { - Less opportunities to learn from } \\
\text { physical exam } \\
\text { - Less time to incorporate } \\
\text { education } \\
\text { - Technological issues }\end{array}$ & $\begin{array}{l}\text { "Sometimes it's hard to connect more emotionally...given the lack of human } \\
\text { presence." } \\
\text { "You cannot provide physical exams, which is not necessary for all visits, but when } \\
\text { needed it does impact the ability to learn about that aspect of clinical care." } \\
\text { "Prone to tech issues which can disrupt the experience." }\end{array}$ \\
\hline $\begin{array}{l}\text { Perceived advantages of } \\
\text { telehealth for } \\
\text { patients/families }\end{array}$ & $\begin{array}{l}\text { - Teens more comfortable in their } \\
\text { home environment } \\
\text { - Increased } \\
\text { accessibility/convenience for } \\
\text { families }\end{array}$ & $\begin{array}{l}\text { "Families seemed appreciative of convenience and the ability to have a visit } \\
\text { virtually, they seemed satisfied with the visits and seemed to feel their goals } \\
\text { were achieved" } \\
\text { "For families that lived far away...the ability to have a telehealth visit mitigated } \\
\text { some access barriers. Some parents were also able to join visits on a short break } \\
\text { from work, which... was very helpful for them." } \\
\text { "More accessible particularly for patients with high risk family members" }\end{array}$ \\
\hline $\begin{array}{l}\text { Perceived disadvantages of } \\
\text { telehealth for } \\
\text { patients/families }\end{array}$ & $\begin{array}{l}\text { - Difficulty building rapport in } \\
\text { new visit } \\
\text { - Lack of vitals/physical exam } \\
\text { - Discomfort discussing sensitive } \\
\text { topics } \\
\text { - Equity/access to technology }\end{array}$ & $\begin{array}{l}\text { "Discussing difficult topics over [telehealth platform] has challenges, and making } \\
\text { sure [patients] have the support after the appointments is tough." } \\
\text { "Empathy from [a] provider may be more difficult to convey or feel less } \\
\text { comforting via screen/speaker." } \\
\text { "New visits... felt a little harder to make a connection, although not impossible." } \\
\text { "Eating disorder visits were limited without vitals and weight." } \\
\text { "Can widen the equity gap when disadvantaged families also have a lot of trouble } \\
\text { using the technology." }\end{array}$ \\
\hline $\begin{array}{l}\text { Recommendations for future } \\
\text { use }\end{array}$ & $\begin{array}{l}\text { - Attendings disabling video } \\
\text { function during visit } \\
\text { - E-huddle/pre-visit huddle } \\
\text { - Post-visit debrief } \\
\text { - Incorporation of telehealth in } \\
\text { training curricula }\end{array}$ & $\begin{array}{l}\text { "Graduating with experience providing care [via telehealth] will be helpful moving } \\
\text { forward." } \\
\text { "The e-huddle" and pre-visit case discussion, [are] so helpful for preparation, as } \\
\text { well as for learning." } \\
\text { "What I did find important was finding } 2-3 \text { minutes after a visit to briefly discuss } \\
\text { pearls or questions that came up between visits." }\end{array}$ \\
\hline
\end{tabular}

and reported unique advantages that were often not afforded with in-person visits. Along with our recent work [17], this is the first study, to our knowledge, to evaluate the effects of telehealth in clinical education in Adolescent Medicine. Similar to prior studies, we found trainees had concerns about inability to observe pertinent physical exam skills during telehealth encounters, reported occasional discomfort holding difficult conversations virtually, and sometimes found it difficult to fit into the conversation $[18,19 \bullet \bullet]$. Over the course of the past year, several articles outlining best practices and standardized visit structures for telehealth precepting have been published and offer some solutions to the challenges this format poses. [19••, 20]. Our study demonstrates that trainees were highly appreciative of direct observation and receiving real-time feedback from their supervising attending, as well as of pre- and post-visit case discussions, and recommended that these strategies be utilized for future telehealth visits. This is consistent with recent literature and is reflected in several publications [19••, 21••,22,23]. Our findings additionally related concern from some trainees regarding technological difficulties and challenges with internet connection, which aligns with recent research demonstrating that connection quality is strongly linked to practitioner's enjoyment of telehealth visits [24]. As such, training programs may consider establishing designated telehealth workspaces for trainees and equipping learners with appropriate devices to allow for ease of access to virtual visits with a stable internet connection.

Our work also echoes findings from studies reporting perceptions that telehealth is a unique skillset essential for the success of future physicians with pleas for ongoing and standardized integration into medical training curricula; however, these studies are primarily based on feedback from medical 
and nursing students, not residents or fellows [10, 12••]. One unanticipated outcome of our study was that trainees reported increased convenience, ease, and efficiency when taking part in clinical encounters via telehealth. Though our results do not explicitly link this to improved trainee wellbeing, this association is likely. As this is not well represented in the current literature, it is worth further exploration.

Strengths of our study include the relatively high response rate among trainees. Given the anonymous web-based survey format there was a low risk of perceived influence or judgment from faculty administering the survey. Feedback was also elicited shortly after completion of clinical rotations, diminishing potential for recall bias. Our study was limited by the relatively small sample size. In addition, due to the swift changes implemented since the pandemic, the experience of different cohorts of trainees varied by rotation block and proficiency of attending physicians with telehealth. Those who rotated in March 2020 had less experience with telehealth than those who rotated later during the study, and attending physicians supervising trainees had more time to fine-tune their teaching strategies via telehealth later in the pandemic.

\section{Conclusion}

Overall, our study found that despite recent shifts in clinical education, trainees have felt telehealth to be a valuable learning modality and hope to see it incorporated in future curricula after the resolution of the pandemic. Continued development and standardization of best practices may facilitate clinical education via telehealth moving forward. We plan to use these preliminary findings to inform a larger-scale study, and to partner with other Adolescent Medicine and pediatric training programs to enhance clinical education via telehealth. As we envision a future in medicine that includes ongoing clinical care utilizing telehealth, it is vital that we continue to seek, evaluate, and refine new educational strategies for training the next generation of pediatric and adolescent health providers.

Acknowledgments We would like to thank the residents and fellows rotating through the Adolescent Medicine Clinic at Seattle Children's for taking the time to complete our questionnaire. We are grateful for their patience and continued engagement during the endless challenges and disruptions to their education that the COVID-19 pandemic has posed.

\section{Declarations}

Conflict of Interest The authors declare no competing interests.

Human and Animal Rights This article does not contain any studies with human or animal subjects performed by any of the authors.

\section{References}

Papers of particular interest, published recently, have been highlighted as:

- Of importance

- Of major importance

1. Anderson ML, Turbow S, Willgerodt MA, Ruhnke GW. Education in a crisis: the opportunity of our lives. J Hosp Med. 2020;15:2879. https://doi.org/10.12788/jhm.3431.

2. Waseh S, Dicker AP. Telemedicine training in undergraduate medical education: mixed-methods review. JMIR Med Educ. 2019;5: e12515-27877. https://doi.org/10.2196/27877.

3. Kong SS, Azarfar A, Ashour A, Atkins C, Bhanusali N. Awareness and attitudes towards telemedicine among medical students in the United States. Cureus. 2020;12:e11574. https://doi.org/10.7759/ cureus.11574. A useful review of telehealth perspectives from medical students.

4. Timm B, O'Connor E, Liodakis P, Jayarajan J, Bolton D. We still need the clinic; patient perceptions on doctor-in-training delivered telehealth versus in-person consultation. ANZ J Surg. 2020;90: 658-9. https://doi.org/10.1111/ans.15884.

5. Sequeira GM, Kidd KM, Coulter RWS, Miller E, Fortenberry D, Garofalo R, et al. Transgender youth perspectives on telehealth for delivery of gender affirming care. J Adolesc Health. 2020;66:S312. https://doi.org/10.1016/j.jadohealth.2020.08.028.

6. Anderson KE, Byrne C, Goodyear A, Reichel R, Le Grange D. Telemedicine of family-based treatment for adolescent anorexia nervosa: a protocol of a treatment development study. J Eat Disord. 2015;3:25. https://doi.org/10.1186/s40337-015-0063-1.

7. Bashshur RL, Shannon GW, Bashshur N, Yellowlees PM. The empirical evidence for telemedicine interventions in mental disorders. Telemed J E Health. 2016;22:87-113. https://doi.org/10. 1089/tmj.2015.0206.

8. Evans YN, Golub S, Sequeira GM, Eisenstein E, North S. Using telemedicine to reach adolescents during the COVID-19 pandemic. J Adolesc Health. 2020;67:469-71. https://doi.org/10.1016/j. jadohealth.2020.07.015. An interesting overview of a telehealth approach to adolescent healthcare.

9. North S. Telemedicine in the time of COVID and beyond. J Adolesc Health. 2020;67:145-6. https://doi.org/10.1016/j. jadohealth.2020.05.024 An editorial on telehealth adaptations during the COVID pandemic.

10. Iancu AM, Kemp MT, Alam HB. Unmuting medical students' education: utilizing telemedicine during the COVID-19 pandemic and beyond. J Med Internet Res. 2020;22:e19667. https://doi.org/ 10.2196/19667.

11. Wayne DB, Green M, Neilson EG. Medical education in the time of COVID-19. Sci Adv. 2020;6:1-2. https://doi.org/10.1126/sciadv. abc7110.

12.• Chike-Harris KE, Durham C, Logan A, Smith G, DuBose-Morris $\mathrm{R}$. Integration of telehealth education into the health care provider curriculum: a review. Telemed J E Health. 2021;27:137-49. https:// doi.org/10.1089/tmj.2019.0261. A useful review of telehealth and educational integration.

13. Emans SJ, Ford CA, Irwin CE Jr, Richardson LP, Sherer S, Sieving RE, et al. Early COVID-19 impact on adolescent health and medicine programs in the United States: LEAH Program Leadership Reflections. J Adolesc Health. 2020;67:11-5. https://doi.org/10. 1016/j.jadohealth.2020.04.010.

14. Barney A, Buckelew S, Mesheriakova V, Raymond-Flesch M. The COVID-19 pandemic and rapid implementation of adolescent and young adult telemedicine: challenges and opportunities for 
innovation. J Adolesc Health. 2020;67:164-71. https://doi.org/10. 1016/j.jadohealth.2020.05.006.

15. Wood SM, White K, Peebles R, Pickel J, Alausa M, Mehringer J, et al. Outcomes of a rapid adolescent telehealth scale-up during the COVID-19 pandemic. J Adolesc Health. 2020;67:172-8. https:// doi.org/10.1016/j.jadohealth.2020.05.025.

16. Carlson JL, Goldstein R. Using the electronic health record to conduct adolescent telehealth visits in the time of COVID-19. J Adolesc Health. 2020;67:157-8. https://doi.org/10.1016/j. jadohealth.2020.05.022.

17. Pham D-Q, Golub SA, Breuner CC, Evans YN. The impact of telehealth on clinical education in Adolescent Medicine during the COVID-19 pandemic: positive preliminary findings. Front Pediatr. 2021;9:642279. https://doi.org/10.3389/fped.2021. 642279.

18. Suarez-Cedeno G, Pantelyat A, Mils K, Murthy M, Alshaikh J, Rosenthal L, et al. Movement disorders virtual fellowship training in times of coronavirus disease 2019: a single-center experience. Telemed J E Health. 2021; Advance online publication. https://doi. org/10.1089/tmj.2020.0419.

19.• Wamsley M, Cornejo L, Kryzhanovskaya I, Lin BW, Sullivan J, Yoder J, et al. Best practices for integrating medical students into telehealth visits. JMIR Med Educ. 2021;7:e27877. https://doi.org/ 10.2196/27877. An overview of strategies to facilitate virtual clinical education.
20. Mills S, Cioletti A, Gingell G, Ramani S. Training Residents in virtual advance care planning: a new twist in telehealth. J Pain Symptom Manag. 2021; Advance online publication. https://doi. org/10.1016/j.jpainsymman.2021.03.019.

21.• Johnson D, Gatewood E, Ling A, Kuo AC. Teleprecepting: a timely approach to clinical education during COVID-19. J Am Assoc Nurse Pract. 2021. https://doi.org/10.1097/JXX. 0000000000000567 . A useful overview of best practices for telehealth precepting.

22. Franklin G, Martin C, Ruszaj M, Matin M, Kataria A, Hu J, et al. How the COVID-19 pandemic impacted medical education during the last year of medical school: a class survey. Life. 2021;11:294. https://doi.org/10.3390/life11040294.

23. Fleming DA, Riley SL, Boren S, Hoffman KG, Edison KE, Brooks CS. Incorporating telehealth into primary care resident outpatient training. Telemed J E Health. 2009;15:277-82. https://doi.org/10. 1089/tmj.2008.0113.

24. Saiyed S, Nguyen A, Singh R. Physician perspective and key satisfaction indicators with rapid telehealth adoption during the coronavirus disease 2019 Pandemic. Telemed J E Health. 2021; Advance online publication. https://doi.org/10.1089/tmj.2020. 0492.

Publisher's Note Springer Nature remains neutral with regard to jurisdictional claims in published maps and institutional affiliations. 